\title{
Evaluating the implementation
} of the standard treatment guidelines (STGs) and essential medicines list (EML) at a public South African tertiary institution and its associated primary health care (PHC) facilities

Tashni Govender, Fatima Suleman and Velisha Ann Perumal-Pillay* ${ }^{*}$

\begin{abstract}
Background: The standard treatment guidelines (STGS) and essential medicines list (EML) were a policy option recommended in the National Drug Policy for South Africa in 1996 to address the irrational and bloated medicines procurement list. STGs/EML serve as a tool to promote cost-effective use of medicines; rational prescribing; and improve accessibility to medicines for all citizens. The purpose of this study was to evaluate the use and implementation of the STGS/EML by prescribers at a public tertiary institution and its associated Primary Health Care (PHC) facilities in the uMhlathuze subdistrict of KwaZulu Natal. The study aimed to provide feedback and to make recommendations to policy makers to improve the use and implementation of the STGs/EML and to inform National Health Insurance (NHI) policy development.
\end{abstract}

Method: An observational quantitative descriptive research design was used. A retrospective audit of prescriptions was conducted, and questionnaires were utilized to collect data from prescribers and the facilities to evaluate the utilization of the STGS/EML and the rational use of medicines. All descriptive analyses were presented as counts with percentages, and Fisher's exact test was used to compare results. The data was summarized, reduced, and analysed using SAS statistics software.

Results: 107 medical doctors (97\%) responded to the questionnaire at hospital level and 98 nurses (98\%) responded to the questionnaire at the PHC level. Results revealed that the majority of doctors, $94.4 \%$, had access to the latest STGS/EML compared with only $41.8 \%$ of nurses. $70.3 \%$ and $78.3 \%$ of doctor's and nurse's prescriptions, respectively, adhered to the guidelines. $94.9 \%$ of nurses requested training on the use of STGs/EML as most of them had not received formal training on its use.

Conclusion: This study showed suboptimal adherence to STGS/EML by all prescribers, in contrast to previous research amongst nurses when hardcopies were available. Training on the use of the STGs/EML is needed at PHC level

Editorial responsibility: Zaheer Babar, University of Huddersfield, UK.

*Correspondence: perumalv@ukzn.ac.za

Discipline of Pharmaceutical Sciences, College of Health Sciences,

University of KwaZulu-Natal, Private Bag X54001, Durban 4000, South

Africa

(c) The Author(s) 2021. Open Access This article is licensed under a Creative Commons Attribution 4.0 International License, which permits use, sharing, adaptation, distribution and reproduction in any medium or format, as long as you give appropriate credit to the original author(s) and the source, provide a link to the Creative Commons licence, and indicate if changes were made. The images or other third party material in this article are included in the article's Creative Commons licence, unless indicated otherwise in a credit line to the material. If material is not included in the article's Creative Commons licence and your intended use is not permitted by statutory regulation or exceeds the permitted use, you will need to obtain permission directly from the copyright holder. To view a copy of this licence, visit http://creativecommons.org/licenses/by/4.0/. The Creative Commons Public Domain Dedication waiver (http://creativeco mmons.org/publicdomain/zero/1.0/) applies to the data made available in this article, unless otherwise stated in a credit line to the data. 
and improved monitoring of STGs/EML compliance is necessary. This study may be replicated for a wider population to paint a national picture and to periodically assess the extent of the implementation of the STGS/EML.

Keywords: Standard treatment guidelines, Essential medicines list, South Africa, Primary and tertiary health care, Rational use of medicines

\section{Background}

To meet the basic constitutional human right to healthcare, the new democratic South African government commissioned a committee to look specifically at medicine issues, which gave rise to the National Drug Policy (NDP) of 1996. The NDP sought to address deficiencies such as the irrational use of medicines, inaccessibility to medicines and cost-ineffective treatment, and inefficient procurement and logistic practices to "ensure an adequate and reliable supply of safe, cost-effective drugs of acceptable quality to all citizens of South Africa and the rational use of drugs by prescribers, dispensers and consumers". The NDP allowed for the provision of the Essential Medicines Lists (EML) guided by the Standard Treatment Guidelines (STGs) through the National Essential Drugs Programme [1]. The NDoH provisioned the development and maintenance of the STGs/EML through the National Essential Medicines List Committee appointed by the Minister of Health, which is supported by the Affordable Medicines Directorate (AMD). The AMD is a directorate with the $\mathrm{NDoH}$ which is responsible for the development of systems to ensure access to essential pharmaceutical services and provides provinces with legislation and policies (regulatory frameworks) to monitor access to medicines [2].

STGs are intended to provide therapeutic guidance that is necessary to treat the prevalent health conditions of a country [3]. The EML is derived from the STGs and consists of a limited range of medicines that are intended to be available at all times in sufficient quantities and are chosen with due regard to efficacy, safety, and affordability [4]. The South African STGs/EML provide background information on each medical condition and recommended treatment regimens linked to the medicines listed in the EML, as well as non-pharmaceutical interventions, per level of care [2].

The STGs are evidence-based guidelines, with an emphasis on efficacy, safety and cost-effectiveness to treat the priority health conditions of a country's population. Using rational medicine selection, the EML streamlines the number of medicines required to treat the prevalent health conditions according to guidelines set by the STGs. This results in a limited number of medicines that need to be procured by the country's public health sector which allows for the efficient allocation of public financial resources; and also streamlines the supply chain process through efficient drug procurement and inventory control; as well as creates competition amongst suppliers translating to lower tender prices leading to greater accessibility to essential medicines and improved health outcomes [3, 4]. STGs/EML utilization in SA is a priority in the public sector but has also been encouraged in the private sector as they serve to standardize patient care and provide a basis to monitor and assess the quality of care; and aids medicine procurement and inventory control processes $[5,6]$. Non-compliance to the STGs/EML results in increased opportunity costs and poor health outcomes such as an increased risk of adverse drug reactions, treatment failure, polypharmacy and antimicrobial resistance, and ultimately results in the inefficient use of resources which directly impacts the availability of medicines [2].

Essential medicines, as a concept, is dynamic and requires the process of selecting medicines to continually review new therapeutic choices according to the healthcare needs and changing disease patterns of the population while ensuring medicine quality, safety and affordability [5]. The EML and the STGs allow provincial formularies to be drawn up. The South African public healthcare sector remains resource-constrained, while the healthcare needs of the population continue to grow. New medicines and treatment regimens continually enter the market with the promise of improved health outcomes, but at a high-cost burden [2]. This requires the revision and review of STGs/EML to ensure that the best available treatments are accessible and financially sustainable.

State healthcare establishments are categorized according to the type of healthcare services rendered in terms of Section 35 of the National Health Act, 2003 (Act No, 61 of 2003). Primary level consists of Primary Health Care (PHC) clinics and community health centres; secondary level consists of district and regional hospitals; and tertiary/quaternary level consists of tertiary and central hospitals [2, 7]. The first STGs/EML were published in 1996 for the primary healthcare level, which was subsequently followed by secondary (hospital) healthcare STGs/EML, and only a recommended EML for tertiary and quaternary healthcare $[5,8]$. To strengthen the public healthcare system and provide widespread access to healthcare, the NDoH introduced a policy in 1996, called "Restructuring the National Health System for Universal Primary 
Health Care" [9]. This policy provided the framework by which PHC services would be rendered and specified the role of a designated group of nurses who served as the backbone of PHC services at public facilities. This policy, along with the country's nursing regulatory body, the South African Nursing Council through the Nursing Act, No. 33 of 2005 as amended, allowed for this specialized group of professional nurses to function independently to diagnose and treat patients at public PHC facilities [9, 10].

Previously, new editions of the STGs/EML were published as hardcopies and disseminated across the country. This approach was met with challenges as the review process was ongoing, resulting in out-dated versions of the guidelines. Thus, the NDoH introduced the first free mobile application for the STGs/EML in 2015 known as the EML Clinical Guide, to improve accessibility to the guidelines and ensure that the latest information was readily available [11]. Since the introduction of the mobile application, there have been no studies done to evaluate the impact on accessibility to the guidelines. There are limited studies conducted in South Africa to evaluate the improvement of medicine use and accessibility through policies, such as the STGs/EML. Particularly, in developing countries, the implementation and evaluation of STGs/EML has not been simple as these countries lack the infrastructure and resources to develop a comprehensive evaluation and monitoring system to evaluate these policies [12].

A global study that analysed the data of 23 countries from the World Health Organization (WHO)/Health Action International database in 2014 looked at the implementation of STGs/EML and found that essential medicines were more available than non-essential medicines in all health care institutions (both public and private) due to essential medicines being prioritized through policy interventions; however, the availability of essential medicines is not yet satisfactory [13]. The average availability of essential medicines in developing countries (SA included) was found to be $34 \%$ in public facilities compared to $63.2 \%$ in the private sector [14].

In SA, poor healthcare infrastructure and high medicine prices were identified as the factors to most adversely affect the implementation of the EML. The lack of resources has resulted in over-strained public health facilities, with limited hospital capacity, personnel shortages, and poor procurement and supply systems, which have further impacted EML implementation in the country [14].

Improved health outcomes and increased life expectancy are considered a social investment; thus, the State recognizes that the implementation of universal health coverage (UHC) is necessary for poverty reduction, sustained economic growth and socio-economic development [15]. To transform an unequal health care system, South Africa is in the process of implementing UHC, through National Health Insurance (NHI), which is a single financing system intended to provide all South Africans with essential health care [16].

NHI will provide medicines on the National Reimbursement Medicines List to patients who are treated in accordance with the STGs; therefore, strategic purchasing and procurement systems must ensure that access to healthcare is improved while delivering services costeffectively and based on scientific evidence by utilizing clinical guidelines (viz. STGs/EML) to guide treatment strategies and prevent excessive use of healthcare services to ensure the sustainability and affordability of the fund [16], hence the need to evaluate the use and implementation of the current STGs/EML in public health institutions and facilities in South Africa to inform such policy changes. There is a need for research of this nature to assess the prescribing of essential medicines and the availability of essential medicines for priority diseases [17]. Therefore, this study aimed to evaluate the implementation and utilization of the STGs/EML by healthcare workers, determine the extent of training and knowledge of prescribers on the use and implementation of these guidelines, and review the rational use of medicines in accordance with the guidelines at service delivery level.

\section{Methodology}

An observational quantitative descriptive research design was used. This allowed the participants to reflect on how the STGs/EML were used within the public healthcare sector at PHC facilities and a tertiary hospital and provided data to make recommendations in practice [18]. To assess the key areas and achieve the objectives of this study three tools were developed and utilized. In part one of the study, a prescription audit was conducted, while in part two, a questionnaire was utilized to collect data from professional nurses and medical doctors at the institution and facilities to evaluate the utilization of the STGs/EML and the rational use of medicines, as well as to determine the extent of training and knowledge of the clinicians on the use of the guidelines. Finally, a tracer medicines list tool was utilized to determine the availability of medicines at each facility. Questionnaires were self-administered (and were in English), and the prescription audit was conducted by the researcher. Participation in the study was voluntary after informed consent was sought and anonymity of participants was maintained as no identifying data was collected. Data was collected from 7th January 2020 to 6th February 2020 during which all facilities were visited by the researcher upon receipt of ethics approval. 


\section{Study site}

The study was conducted within the subdistrict of uMhlathuze in the King Cetswhayo district of the province of KwaZulu-Natal at a tertiary hospital and 13 of its associated PHC clinics. The tertiary hospital also functions as a level 1 and level 2 hospital that caters to referrals from 18 hospitals in the northern KwaZulu Natal region [19].

\section{Sample recruitment}

Questionnaires were distributed and prescribers' prescription audits were conducted in 13 PHC clinics and 1 tertiary public hospital. Professional nurses at the primary care level were selected to be surveyed, as they function as prescribers in frontline care at public primary healthcare facilities in SA, as well as medical doctors at the hospital [9]. Medical doctors were approached, in person, from varying disciplines and levels (from interns to heads of clinical units). All participants were approached by the researcher on-site and were provided with an information sheet, which explained what the study was about and why they were being asked to participate, as well as an informed consent form which was signed by the participant before commencement. The participants were informed that they could withdraw from the study at any point.

\section{Inclusion and exclusion criteria for the questionnaire part of the study}

Inclusion criteria:

- Professional nurses at PHC level who were qualified to prescribe.

- Doctors at hospital level.

Exclusion criteria:

- Feedback from participants who withdrew consent.

- Nurses who were not qualified to prescribe, such as enrolled nurses, student nurses and nurses based at hospitals.

\section{Inclusion and exclusion criteria for the prescription audit part of the study \\ Inclusion criteria:}

- Patient records that contained a prescription with prescribed medicines within the previous 3 months of the researcher's visit to the facility were assessed. The most recent prescription was evaluated to ensure that the prescribed treatment was in accordance with the latest guidelines.

- All prescriptions, irrespective of patient demographics or prescribed treatment, were included to allow for a full evaluation of the STGs/EML.

\section{Exclusion criteria:}

- Doctors from the mother hospital consult at each PHC facility once a week, thus doctor's prescriptions at PHC level were excluded from the PHC prescription sample.

- Prescribers are required to indicate their qualification when signing a prescription; where no qualification was indicated the prescription was not included in the sample.

- Patient records that did not contain a prescription with prescribed medicines within the previous 3 months of the researcher's visit to the facility.

\section{Sampling}

All sample size calculations were performed by a statistician and allowed for a 5\% margin of error with a 95\% level of confidence. The formula used to calculate all sample sizes was

$$
n=N * X /(X+N-1),
$$

where

$$
X=Z a / 22 * p *(1-p) / E 2
$$

and $Z a / 2$ is the critical value of the normal distribution at $\alpha / 2, E$ is the margin of error, $p$ is the sample proportion, and $N$ is the population size. A finite population correction was applied to the sample size formula.

\section{Prescription audit sample size}

The number of prescriptions recorded at the hospital per month was 6635 , thus the minimum sample size of medical doctors' prescriptions to be reviewed was calculated to be 37. The collective number of prescriptions recorded at the 13 PHC clinics per month was 46,966, thus the minimum sample size of nurses' prescriptions to be reviewed was calculated to be 263 . This sample size was divided proportionally to show the number of prescriptions to be reviewed per clinic (Table 1).

\section{Questionnaire sample size}

The total number of medical doctors at the hospital was 147, thus 107 was the minimum sample size recommended to be surveyed. The total population of prescribing nurses was 134 at the 13 PHC facilities, thus 98 
Table 1 Proportional questionnaire and prescription audit sample sizes at PHC facilities

\begin{tabular}{lllll}
\hline Clinic & $\begin{array}{l}\text { No. of prescribing } \\
\text { nurses }\end{array}$ & $\begin{array}{l}\text { No. of nurses to be surveyed for } \\
\text { questionnaire }\end{array}$ & $\begin{array}{l}\text { No. of prescriptions per } \\
\text { month }\end{array}$ & $\begin{array}{l}\text { No. of prescriptions to be } \\
\text { reviewed for prescription } \\
\text { audit }\end{array}$ \\
\hline Facility 1 & 18 & 13 & 7240 & 41 \\
Facility 2 & 16 & 12 & 2837 & 16 \\
Facility 3 & 16 & 12 & 6239 & 35 \\
Facility 4 & 4 & 3 & 1460 & 8 \\
Facility 5 & 4 & 3 & 2400 & 13 \\
Facility 6 & 17 & 12 & 4814 & 27 \\
Facility 7 & 16 & 12 & 7124 & 40 \\
Facility 8 & 5 & 4 & 1659 & 6 \\
Facility 9 & 4 & 3 & 1005 & 10 \\
Facility 10 & 9 & 6 & 1787 & 12 \\
Facility 11 & 8 & 6 & 2185 & 38 \\
Facility 12 & 11 & 8 & 6801 & 8 \\
Facility 13 & 6 & 4 & 1415 & 263 \\
Total & 134 & 98 & 46,966 & 3 \\
\hline
\end{tabular}

nurses was the minimum sample size recommended to be surveyed. This sample size was divided proportionally to show the number of nurses to be surveyed per clinic in the table (Table 1).

\section{Data collection tools and data collection process Tool development and data collection process}

The study evaluated the use and implementation of the STGs/EML by assessing the following key areas:

\section{- Accessibility to STGs/EML:}

Determination of the accessibility of the STGs/EML to prescribers gave insight into how the guidelines have been used and implemented, and whether the STGs/EML policy had resulted in greater accessibility of the guidelines at the grassroots level.

- Frequency of use of the STGs/EML: Reporting on the frequency of use of the STGs/EML by prescribers gave insight into how the guidelines have been used and implemented, and whether the introduction of the STGs/EML had been a necessary and useful tool at the grassroots level.

- Availability of medicines:

The STGs/EML were introduced to improve the accessibility of essential medicines to patients. Determination of the availability of essential medicines gave insight into how the guidelines have been utilized and implemented, and whether the STGs/EML policy had resulted in greater accessibility of medicines to, and improved treatment of patients.
- Rational use of medicines and adherence to the STGs/EML:

Clinicians' diagnosis/es were compared to the medicines prescribed in accordance with the STGs/EML which provided insight into whether the STGs/EML policy had ensured that the healthcare needs of patients were appropriately and safely met.

- Training and knowledge on use of the STGs/EML: The extent of training and knowledge on the use of the STGs/EML of prescribers by assessing prescribers' responses on whether they had received formal training on how to use the STGs/EML, whether they were confident in their knowledge on how to use the STGs/EML and whether they wished to receive training on how to use the STGs/EML was assessed. This gave insight into how well the STGs/EML were understood at grassroots level and whether interventions were required to improve use of the guidelines.

The development of the three data collection tools was adapted from the first impact study conducted in South Africa by the South African Drug Action Programme in 1999 after the introduction of the first EML [20]. Data was collected using the three tools as follows:

1. The prescription audit tool was developed to determine the rational use of medicines at the facilities in line with STGs/EML recommendations to evaluate adherence to the guidelines by surveying prescriptions retrospectively. The prescription audit tool was designed to allow the researcher to record the diagnosis and treatment prescribed on the prescriptions sampled and then record whether the prescribed 
medicines were available on the latest EML and if the treatment prescribed complied with STG recommendations. The prescription audit was piloted by the researcher at a facility to determine the validity and ease of use of the tool, after which no changes to the prescription audit tool were found to be necessary. The prescription audit was conducted by the researcher on-site by observation to collect the data. Upon visiting each facility, the researcher evaluated prescriptions in the patient records, as per sampling protocol to document treatment compliance and the availability of the prescribed medicine. Systematic sampling was employed, i.e., every third prescription was analysed to increase representativeness and was easy to implement [21]. The prescribed medicines were reviewed against the STGs/EML to determine the appropriateness of treatment and the adherence of prescribed medicines to the STGs/EML. Prescriptions were considered as non-adherent to the STGs/EML if the incorrect medicines or regimens were prescribed in relation to the diagnosis according to the guidelines, the medicines were redundant, a medicine was contraindicated, the incorrect dose, medicine or duration of treatment was prescribed, polypharmacy was present, and if no diagnosis was recorded as it is legally required and necessary to determine rational medicine prescribing [22].

2. Questionnaire for survey: A self-administered questionnaire was developed and utilized which sought personal input from the participants on their experience with the use of the STGs/EML. The questions were closed-ended to quantify the responses. The questions sought to determine whether the prescribers had access to the latest STGs/EML (viz. the mobile application, EML Clinical Guidelines, and soft copies available from the $\mathrm{NDoH}$ website); had received training on how to use the STGs/EML; whether they would like to receive training on how to use the STGs/EML; and how often they had used the guidelines. For the purpose of this study the STGs/ EML were considered accessible if available to the prescriber when required. In this study the STGs/ EML were deemed accessible if the prescriber had access to the mobile app which contained the most up-to-date guidelines as hardcopies of the STGs/ EML were no longer available and out-dated. The frequency of use of the STGs/EML was self-reported by prescribers by stating how often they used the STGs/ EML by choosing from the options presented in the questionnaire. The questionnaire and a consent form were handed to the participants by the researcher for self-completion. The questionnaire was piloted with 10 prescribers from two facilities (both doctors and nurses) to ensure comprehension of the questions, ease of use and to rule out ambiguity. It was found that no changes to the questionnaire were required after being piloted.

3. Tracer medicines list tool: The National Core Standards (NCS) for health establishments in South Africa was developed as a benchmark to measure performance and maintain standards of quality health care and service delivery in all health facilities [23]. The tracer list tool used in this study to measure the number of key medicines available was based on a condensed list of medicines from the EML that were chosen as part of the NCS audit tool to monitor the availability of those essential medicines to evaluate the implementation of the STGs/EML. The tool listed 33 medicines, in the form of a checklist, and allowed the researcher to record whether each medicine on the tracer medicines list was present or absent in the pharmaceutical storeroom of each facility. This allowed the researcher to assess whether the essential medicines within the basket were accessible to patients if it was prescribed, and whether medicines prescribed by the clinician were listed in the STGs/EML to determine whether the pharmaceutical health needs of the patients were met. The designation of a medicine on an EML is dependent on its dosage form and indication, not its pack size. A medicine on the checklist was considered to be available if the listed item was present in the stated dosage form and strength (to account for paediatric and adult dosing requirements), regardless of the quantity present, within the pharmaceutical storeroom of the facility. The tool was piloted at one facility to determine the validity and ease of use of the tool, after which no changes to the tracer list tool were found to be necessary.

A data collection summary tool was developed and utilized to collate data collected using the prescription audit tool, questionnaire and tracer medicines list tool to measure the impact of the STGs/EML on medicine utilization and rational prescribing which allowed for easy analysis.

\section{Data analysis}

All descriptive analyses which were stratified by designation (doctor/nurse) and site (clinic/hospital) were presented as counts with percentages. The Fisher's exact test was used to compare the use and implementation of the STGs/EML, rational use of medicines at the institution in line with STGs/EML recommendations, the extent of training and knowledge on the use and implementation of the STGs/EML by healthcare professionals at the 
institution and facilities. This allowed the data to be summarized meaningfully and show patterns that emerged [24]. The data was reduced and analysed with the help of a statistician using SAS statistics software version 9.4 (SAS Institute INC., Cary). A two-tailed value of $p<0.05$ was considered to indicate statistical significance.

\section{Ethical considerations}

This study was approved by UKZN Biomedical Research Ethics Committee (approval number BE541/17) and the KwaZulu-Natal Department of Health National Health Research Database (Ref: KZ_201805_014). Participants were provided with an information sheet which explained what the study was about and why they were asked to participate-if the participant agreed to participate in the study they were required to sign and date a declaration of informed consent form.

No identifying data from the participants or patients were collected and used in this study, thus participation remained anonymous. Participation was completely voluntary, and participants were made aware that they could withdraw from the study at any stage without consequence. There were no incentives or direct benefits offered to the participants to participate.

\section{Results}

\section{Demographics of the sample}

A total of 107 medical doctors (97\%) responded to the questionnaire at hospital level and a total of 98 nurses (98\%) responded to the questionnaire at the PHC level (Table 2).

\section{Analytical information}

Table 3 (below) contains the combined results from the prescription audit (part one) and the questionnaire (part two) as the outcomes are presented according to the objectives of the study. Results for each respective part of the study are indicated by a key within the table.

Within each category of prescriber, viz. doctors and nurses, the number of prescriptions and the number of prescribers analyzed are indicated by a key within the table.

Within the prescriber category of doctors, the number of prescriber questionnaires analyzed was $n=107$ and the number of prescriptions audited was $n=37$. Within the prescriber category of nurses, the number of prescriber questionnaires analyzed was $n=98$ and the number of prescriptions audited was $n=263$.

Most doctors had access to the latest STGs/EML $(94.4 \% ; n=101)$, which is now available as a mobile

Table 2 Demographic information of participants

\begin{tabular}{|c|c|c|c|c|}
\hline \multirow[t]{2}{*}{ Demographic parameter } & \multicolumn{2}{|c|}{ Doctors $(n=107)$} & \multicolumn{2}{|c|}{ Nurses $(n=98)$} \\
\hline & Frequency & Percentage (\%) & Frequency & Percentage (\%) \\
\hline \multicolumn{5}{|l|}{ Age (years) } \\
\hline $20-29$ & 17 & 1.89 & 21 & 21.43 \\
\hline $30-39$ & 39 & 36.45 & 41 & 41.84 \\
\hline $40-49$ & 38 & 35.51 & 27 & 27.55 \\
\hline $50+$ & 13 & 12.15 & 9 & 9.18 \\
\hline Average age & 39 & & 37 & \\
\hline \multicolumn{5}{|l|}{ Gender } \\
\hline Male & 66 & 61.68 & 9 & 9.18 \\
\hline Female & 41 & 38.32 & 89 & 90.82 \\
\hline \multicolumn{5}{|l|}{ Experience (years) } \\
\hline $1-4$ & 22 & 20.56 & 25 & 25.51 \\
\hline $5-9$ & 32 & 29.91 & 32 & 32.65 \\
\hline $10-14$ & 34 & 31.77 & 29 & 29.59 \\
\hline $15+$ & 19 & 17.76 & 12 & 12.25 \\
\hline Average years of experience & 9 & & 8 & \\
\hline \multicolumn{5}{|l|}{ Qualification/level } \\
\hline Intern & 18 & 16.82 & & \\
\hline Community service & 11 & 10.28 & & \\
\hline Medical officer & 69 & 64.49 & & \\
\hline Specialist & 9 & 8.41 & & \\
\hline Professional nurse & & & 98 & 100 \\
\hline
\end{tabular}


Table 3 Prescription audit (part one) and questionnaire (part two) results assessing the implementation of the STGS/EML

\begin{tabular}{|c|c|c|c|c|c|c|c|c|}
\hline & \multicolumn{3}{|c|}{ Doctor (hospital) } & \multicolumn{4}{|c|}{ Nurse (PHC) } & \multirow[t]{2}{*}{$p$ value } \\
\hline & $n$ & Frequency & $\%$ & $n$ & Frequ & ency & $\%$ & \\
\hline \multicolumn{9}{|l|}{ Use and implementation of the STGs/EML } \\
\hline Prescribers with access to the latest STGs/EML (mobile application) ${ }^{\#}$ & $107^{\beta}$ & 101 & 94.4 & $98^{\beta}$ & 41 & & 41.8 & $<0.001$ \\
\hline Prescribed medicines that required buy-outs for non-EML item* & $37^{a}$ & 2 & 5.4 & $263^{a}$ & 0 & & 0 & 0.015 \\
\hline \multicolumn{9}{|l|}{ Frequency of use of the STGS/EML by prescribers $\#$} \\
\hline Often & $107^{\beta}$ & 17 & 15.9 & $98^{\beta}$ & 77 & & 78.6 & $<0.001$ \\
\hline Sometimes & $107^{\beta}$ & 85 & 79.4 & $98^{\beta}$ & 21 & & 21.4 & \\
\hline Rarely & $107^{\beta}$ & 5 & 4.7 & $98^{\beta}$ & 0 & & 0 & \\
\hline Never & $107^{\beta}$ & 0 & 0 & $98^{\beta}$ & 0 & & 0 & \\
\hline \multicolumn{9}{|l|}{ Rational use of medicines and compliance to STGs/EML } \\
\hline Prescriptions with diagnosis recorded* & $37^{a}$ & 26 & 70.3 & $263^{a}$ & 206 & 78.3 & & \\
\hline Prescriptions with diagnosis listed in the STGs/EML* & $37^{a}$ & 23 & 62.2 & $263^{a}$ & 201 & 76.4 & & \\
\hline Prescription adhered to STGs/EML* & $37^{a}$ & 20 & 54.1 & $263^{a}$ & 157 & 59.7 & & \\
\hline \multicolumn{9}{|l|}{ Extent of training and knowledge of STGs/EML } \\
\hline Prescribers trained on the use of the STGs/EML ${ }^{\#}$ & $107^{\beta}$ & 11 & 10.3 & $98^{\beta}$ & 17 & 17.3 & & 0.158 \\
\hline Prescribers knowledgeable on the use of the STGs/EML $\#$ & $107^{\beta}$ & 100 & 93.5 & $98^{\beta}$ & 33 & 33.7 & & $<0.001$ \\
\hline Prescribers who wish to receive training on the use of the STGs/EML\# & $107^{\beta}$ & 39 & 36.4 & $98^{\beta}$ & 93 & 94.9 & & $<0.001$ \\
\hline
\end{tabular}

phone app, but only $(41.8 \% ; n=41)$ of nurses surveyed had access to the latest guidelines. The majority of doctors stated that they sometimes used the STGs/EML $(79.4 \% ; n=85)$ vs $(21.4 \% ; n=21)$ of nurses, whereas the majority of nurses used the STGs/EML often (78.6\%; $n=77)$ vs $(15.9 \% ; n=17)$ of doctors. $(4.7 \% ; n=5)$ of doctors used the STGs/EML rarely. None of the doctors or nurses stated never using the STGs/EML.

Of the prescriptions surveyed, two non-EML items (5.4\%) were prescribed in the hospital level prescriptions which required a buy-out, where a medicine that is not on the EML is required for a patient. None of the PHC level prescriptions required a buy-out.

Only $(10.3 \% ; n=11)$ of doctors and $(17.3 \% ; n=17)$ of nurses stated that they had received training on the use of the STGs/EML, yet $(93.5 \% ; n=100)$ of doctors considered themselves knowledgeable on the use of STGs/EML, whereas only $(33.7 \% ; n=33)$ of nurses responded positively. Most nurses wish to receive training on the use of the STGs/EML $(94.9 \% ; n=93)$, but only $(36.4 \% ; n=39)$ of doctors responded similarly.

Doctors and nurses scored similarly for indicating the diagnoses on the prescriptions $(70.3 \% ; n=26)$ and (78.3\%; 206), respectively. Of those prescriptions, $(62.2 \%$; $n=23$ ) of doctors' diagnoses were listed in the STGs and $(76.4 \% ; n=201)$ of the nurses' diagnoses were found in the STGs. $(54.1 \% ; n=20)$ of doctors' and $(59.7 \% ; n=157)$ of nurses' prescriptions adhered to the STGs/EML. $62.2 \%$ of the diagnoses recorded by doctors and $76.4 \%$ by nurses were listed in the STGs. Due to the lack of recorded diagnoses on prescriptions, the findings for the lack of adherence to the STGs/EML may not be purely due to irrational prescribing and may also affect the number of diagnoses found listed in the STGs/EML. All facilities had between $(93.9 \% ; n=31)$ to $(100 \% ; n=33)$ availability of the basket of tracer medicines. 10 of the 14 facilities surveyed had $(100 \% ; n=33)$ of the tracer medicine available (Table 4).

\section{Discussion \\ Main findings}

The STGs/EML were much more accessible amongst doctors (who are based at the hospital in a more urban area) than nurses (who are based at clinics, often, in rural settings). The latest STGs/EML are now only available as a soft-copy on the $\mathrm{NDoH}$ website and as a mobile app. Prior to the mobile application being made available, after extensive peer-review revision, new editions of the STGs/EML were published every 3 years as hardcopies and distributed to public healthcare workers across the country. This approach resulted in many flaws as the review process is ongoing, resulting in frequently updated guidelines, and consequently out-dated versions of the guidelines were being utilised at institutions. To 
Table 4 Tracer medicines available per facility

\begin{tabular}{lll}
\hline Facility & Frequency & $\begin{array}{l}\% \\
\text { Medicines } \\
\text { available }\end{array}$ \\
\hline Facility_1 & 33 & 100 \\
Facility_2 & 32 & 97 \\
Facility_3 & 33 & 100 \\
Facility_4 & 32 & 97 \\
Facility_5 & 33 & 100 \\
Facility_6 & 33 & 100 \\
Facility_7 & 33 & 100 \\
Facility_8 & 33 & 100 \\
Facility_9 & 31 & 93.9 \\
Facility_10 & 33 & 100 \\
Facility_11 & 33 & 100 \\
Facility_12 & 33 & 100 \\
Facility_13 & 32 & 97 \\
Facility_14 & 33 & 100 \\
\hline
\end{tabular}

combat this, the $\mathrm{NDoH}$ introduced the first free mobile application for the PHC STGs/EML in late 2015 and subsequently included the hospital level STGs/EML in 2017, known collectively as the EML Clinical Guide. This was intended to improve accessibility to the guidelines and ensure that the latest information was readily available as the ownership of mobile phones is widespread and continually growing in SA [11]. The majority of doctors had access to the STGs/EML through the mobile app, compared to very few nurses. Challenges in accessing the latest STGs/EML, particularly amongst nurses, may be the lack of technological know-how and inability to navigate the internet and the app, personal data costs and the lack of access to a smartphone or computer. PHC facilities are also often located in distant and under-serviced areas, where internet access and mobile phone reception is poor. Although not formally surveyed, most respondents at PHC level revealed that they were not aware that the latest STGs/EML were available as a mobile app and that the hardcopies were out-of-date as the STGs/EML have been updated electronically.

Overall compliance to STGs/EML was found to be suboptimal, although the lack of compliance to STGs/ EML was largely due to the lack of recording of diagnoses for both categories of clinicians. The lack of diagnoses was considered as non-compliant to the guidelines for the purpose of this study as the stating of diagnoses is a medico-legal requirement which may have resulted in an over or under-estimation of actual irrational medicine prescribing [22]. Nurses scored marginally better than doctors in both adherence to guidelines and the stating of diagnoses. The lack of adherence to guidelines can be affected by the complexity of both the diagnosis and the guidelines itself-where nurses see simpler, primary health care conditions for which treatment guidelines are straight-forward and the more complex health conditions (which may include multiple diagnoses) are referred to hospital to be seen by doctors and may have more complex diagnoses [25]. It is unknown whether the lack of recorded diagnoses was due to uncertainty of the diagnosis or simply the lack of recording it.

Although very few prescribers from both categories had received training on the use of the STGs/EML, the majority of doctors considered themselves knowledgeable on the use of the STGs/EML and did not wish to receive training on the use of the STGs/EML-a finding that was in stark contrast to the findings amongst nurses who wished to receive training. This result may indicate the ease of use of the mobile app by those familiar with and adept at using technology.

The majority of doctors stated that they sometimes use the STGs/EML, whereas the majority of nurses stated that they often used the guidelines, indicating that the STGs/EML are integral to developing treatment plans for patients. Prescribers are reliant upon those guidelines as all prescribers make use of the guidelines, yet less than half of all nurses had access to the latest STGs/ EML which may result in suboptimal treatment plans for patients and impact the adherence to guidelines. Only a small number of doctors reported using the STGs/EML rarely which may be related to their field and the complexity of patients' conditions as well as the prescriber's experience.

The STGs/EML were introduced to improve rational medicine prescribing and improve availability and accessibility to medicines by streamlining the number of key medicines required to treat the health needs of a country, thereby improving the supply chain management and drug procurement systems [5]. The findings in this study indicate that EML do not guarantee absolute availability as stock-outs do occasionally occur, but the introduction of the STGs/EML has had a positive effect on the availability of essential medicines as most facilities had all the key basket medicines available upon inspection with only 4 facilities scoring between 97 and $93.9 \%$, which well exceeded the WHO target of $80 \%$ [26]. This may be due to the surveillance systems, which utilize software for the weekly reporting of stock levels by clinics and hospitals, introduced in 2016 by the $\mathrm{NDoH}$ to proactively monitor stock levels to prevent stock-outs $[27,28]$.

The use of medicines not listed in the EML, termed non-EML medicines, is possible at state facilities on an individual patient basis. The principle of making nonEML medicines available in state facilities ensures equitable access to medicines as some health conditions 
may not respond to medicines and guidelines as per the STGs/EML. Non-EML medicines which do not have an attached STG must have a treatment protocol which follows the same format as the national STGs/EML to guide the use of the medicine and must be prepared by the relevant Pharmaceutical Therapeutics Committee. A prescription for a non-EML medicine must be accompanied by an approved application form containing a motivation for use submitted by the treating clinician for approval [2].

Two non-EML medicines were prescribed which required a buy-out utilizing applications for the use of non-EML medicines on a "named patient" basis, which indicated that the majority of the prevalent health conditions of the population were provisioned for by the treatment guidelines but that some exceptions to care exist in rare instances. STGs/EML provide recommendations based on the best clinical evidence available but are there to serve as a guide and cannot replace sound clinical judgement [25].

\section{Comparisons with other studies}

The inaccessibility to treatment guidelines, particularly at the PHC level, is a common problem in Africa. Nine years after the introduction of STGs in Nigeria, a study found that $70 \%$ of clinicians did not have access to guidelines [29], these findings were echoed by a study in Botswana and Sudan, despite the guidelines being freely available online [30,31]. Four of the earliest surveys in SA to evaluate the accessibility of STGs/EML amongst healthcare workers were conducted between 1996 and 2005 [32-35]. The number of prescribers with access to the STGs/EML rose considerably from 59\% in 1998 to $97 \%$ in 2003 [32-34]. The 2005 survey considered the STGs/ EML accessible if one guideline document was present within a public hospital and reported $100 \%$ accessibility [35]. Sooruth et al. (2015) [36] conducted a study in 2013 in the uMgungundlovu district of KwaZulu Natal, when hardcopies of the STGs/EML were in circulation in SA, and found that $100 \%$ of the nurses sampled had access to the STGs/EML. This is in stark contrast to the findings of this study amongst PHC nurses, who considerably lacked access to the online guidelines. After the STGs/EML were updated in SA in 2014, roadshows on the development processes of the STGs/EML were conducted in 2015 in three provinces, where it was found that over half the participants were not aware of the updated guidelines. Towards the latter part of the roadshow in 2016, after the introduction of the STGs/EML Clinical mobile app in late 2015 , another survey revealed that just under $60 \%$ of participants at the roadshow surveyed were aware of the PHC STGs/EML mobile app and under $40 \%$ had used the app [11]. The lack of accessibility to the STGs/EML amongst PHC clinicians in this study suggests that the move to online STGs/EML may not have had the desired outcome of improved accessibility to the most up-to-date guidelines amongst all categories of healthcare workers, or that the roadshows were not successful and other educational interventions are required.

The lack of compliance to the STGs/EML of both doctors' and nurses' prescriptions can be largely attributed to the lack of recording of diagnoses in patient records. Likewise, Gasson et al. (2018) conducted a study in Cape Town, South Africa, which found that $30.5 \%$ of prescriptions had an unknown diagnosis during a study into antibiotic prescribing adherence to treatment guidelines and that doctors were less likely to record a diagnosis than nurses [37], in line with the findings of this study.

This study's suboptimal guideline compliance findings were consistent with the many adherence studies conducted internationally in several counties, viz. Nigeria, Sierra Leone, United States of America, Switzerland and Palestine [38-42]. An Italian review that explored reasons for non-compliance to treatment guidelines found that more than $10 \%$ of prescribers ignored available treatment guidelines, prescribers were not fully aware of the contents of treatment guidelines and $10 \%$ of prescribers disagreed with the contents for various reasons, including the lack of credibility of the information provided, and the loss of autonomy in choosing treatment options [43].

There have also been numerous surveys on the adherence to treatment guidelines in SA, usually focusing on specific medicines or health conditions, often only at the primary care level, which have found that treatment compliance amongst prescribers is poor [31, 37, 44-48]. However, the overall adherence to STGs/EML amongst nurses in a study by Sooruth et al. (2015) was found to be exceptionally high at $90.83 \%$ and all respondents selfreported having adhered to guidelines-it must also be noted that the study was conducted in 2013, before the hard copies of the STGs/EML were updated and were only made available electronically in late 2015 [35]. This study's suboptimal compliance findings may further suggest that the phasing out of hardcopies at PHC level has not had the desired effect of increased accessibility to the latest guidelines.

Along with these findings, Sooruth et al. (2015) [36] also found that STGs/EML training amongst nurses in primary care was insufficient with less than $60 \%$ of professional nurses who had obtained a qualification that equipped them with knowledge in assessing, diagnosing, and treating patients in line with STGs/EML. Current in-service training programmes for professional nurses were found to be inadequate and ineffectively implemented as many nurses were employed 
without having attained the appropriate qualification and relied on inadequate "on-the-job" learning due to the increased demand for nurses and gross staff shortages at state facilities, leading to poor job satisfaction [49]. The availability of medicines has increased drastically, since the initial studies were conducted in 1998 in two South African provinces [50], as was evident upon auditing both PHC and hospital-level facilities.

\section{Limitations}

This study was only conducted at public healthcare institutions and facilities within one of the many subdistricts of South Africa, thus may not paint a national picture nor provide a full evaluation of how the guidelines are utilized and implemented and may have implications when looking to generalize the results against wider populations across the country. Response to the self-administered questionnaire was the prerogative of the participant which could be subjective.

The prescription analysis relied on the recordkeeping abilities of the prescribers which may have impacted the results-this was particularly seen in the lack of recording of diagnoses. As this study was done retrospectively, with access only to patient records, diagnoses could not be verified; and where the diagnosis was not recorded it was regarded as non-adherent to the guidelines which may have impacted the results as the treatment could either have been correctly or incorrectly prescribed. The study relied on quantitative data only thus did not fully investigate clinicians' experience with the utilization of the STGs/EML. The prescribing of treatment is nuanced, and the various aspects of the patient should be considered, such as the severity of the condition, co-morbidities, concurrent medication, demographic data and the patient's right to refuse treatment. These factors may have influenced the clinicians' judgement to prescribe contrary to the treatment guidelines which was not considered as clinicians and patients were not interviewed.

\section{Strengths and novelty of study}

There have been no studies conducted in SA to evaluate the implementation and utilization of the STGs/EML prior to the introduction of the STGs/EML policy and few thereafter. This study has shed light on aspects of the implementation outcomes of these policies at the service delivery level and provides a baseline by which future utilization and implementation studies can be compared to. The findings provide a grassroots picture of how the STGs/EML have been utilized and implemented at institutional (secondary and tertiary) and facility (primary) health care levels and may serve as a yardstick by which pertinent post-NHI policy outcomes can be measured.

\section{Recommendations}

The healthcare landscape is constantly evolving with changing healthcare needs resulting in similarly changing learning needs of healthcare workers. To meet these needs, Norushe et al. (2004) [49] outlined interventions to improve in-service training programmes after conducting a study amongst PHC clinicians in East London, South Africa. Implementation of a skills assessment followed by an orientation programme for all new staff members on the use of the STGs and EML is recommended, as well as regular in-service training to reinforce and update the knowledge and skills of prescribers, particularly when the STGs/EML are updated, in line with interventions to monitor medicine policies recommended by the WHO [51], particularly at the PHC level. The reintroduction of hardcopies should be considered at PHC level to increase accessibility to the STGs/EML to ensure that the latest treatment guidelines are available until the accessibility to technology has improved. Access to mobile technology continues to grow [11], thus targeted training on how to access and utilize the EML Clinical Guide app should be prioritized for PHC prescribers to encourage usage of the mobile app.

The National Guidelines for the Establishment and Functioning of PTCs in South Africa was developed in 2019 to enact the National Policy for the Establishment and Functioning of PTCs of 2015. PTCs are responsible for ensuring that medicine related policies, such as the STGs/EML are implemented at all levels of care. A function of the PTC is to monitor and ensure rational medicine use and monitor prescribing practices in line with the STGs/EML [2], but the extent to which this is done at facility level has not been studied previously. It is essential that STGs/EML compliance and monitoring protocols are strengthened to ensure continued adherence to the guidelines, particularly regarding the compulsory recording of diagnoses in patient records. The utilization of electronic prescribing will improve adherence to guidelines, improve the quality of patient records and enhance the monitoring of prescriptions.

This study did not analyse the possible reasons for non-compliance to the STGs/EML, such as polypharmacy, incorrect dose and/or duration of treatment, lack of indication for prescribed medicine, incorrect treatment for diagnosis, etc.-targeting this area for future studies may identify gaps for targeted interventions and education. Future studies assessing the impact on health outcomes of patients upon introduction of the STGs/EML should be explored to provide a holistic picture of the impact that the utilization of STGs/EML 
has had. Research of this nature should be ongoing to act as a barometer to which successes and shortfalls of the implementation of such policies can be measured as this study can be replicated for a wider population to paint a national picture.

\section{Conclusion}

The South African $\mathrm{NDoH}$ has been proactive in strengthening the healthcare system for its citizens as evidenced by the introduction of the STGs/EML, which has ensured good availability of essential medicines in the public sector and has been successful at providing adequate treatment for the prevalent health conditions in SA, thus has made essential medicines more accessible to the population, although, this study found that more robust monitoring and improved protocols are necessary to address the gaps found in the implementation of the STGs/EML to create more succinct and quality guidelines, and improve the utilization of the guidelines, thereby ensuring that quality and sustainable healthcare is accessible to all.

The STGs/EML provide evidence-based recommendations for rational prescribing of medicines, and while they cannot replace sound clinical judgement, they ensure standardized quality of patient care and promote access to quality and sustainable healthcare. As South Africa moves towards NHI implementation, utilization of the STGs/EML will guide treatment strategies and prevent excessive use of healthcare services to ensure the sustainability and affordability of the fund [4]. The research this study has provided intends to inform policies involved in the development and implementation of $\mathrm{NHI}$ and provide novel recommendations for improvement of the current Essential Medicines Programme as improved health outcomes are evidenced by accessible and quality medicines. Processes to monitor adherence to STGs/EML must be strengthened as these guidelines will dictate the healthcare services rendered upon $\mathrm{NHI}$ implementation.

\section{Abbreviations \\ AMD: Affordable Medicines Directorate; EML: Essential medicines list; NCS: National Core Standards; NDoH: National Department of Health; NDP: National Drug Policy; NHI: National Health Insurance; PHC: Primary Health Care; SA: South Africa; STGs: Standard treatment guidelines; UHC: Universal health coverage; WHO: World Health Organization.}

\section{Acknowledgements}

Nobuhle Mchunu (Statistician, Biostatistics unit, South African Medical Research Council, Durban, South Africa, University of KwaZulu-Natal, School of Mathematics, Statistics and Computer Science, Pietermaritzburg, South Africa).

\section{Authors' contributions}

VAPP and FS conceptualised the study. TG conducted data collection and analysis and drafted the manuscript. VAPP and FS undertook data validation and contributed to the writing of the manuscript. All authors read and approved the final manuscript.

\section{Funding}

"Research reported in this publication was supported by the Fogarty International Center (FIC), NIH Common Fund, Office of Strategic Coordination, Office of the Director (OD/OSC/CF/NIH), Office of AIDS Research, Office of the Director (OAR/NIH), National Institute of Mental Health (NIMH/NIH) of the National Institutes of Health under Award Number D43TW010131. The content is solely the responsibility of the authors and does not necessarily represent the official views of the National Institutes of Health". "Research reported in this publication was supported by the South African Medical Research Council under a Self-Initiated Research Grant. The views and opinions expressed are those of the author(s) and do not necessarily represent the official views of the SA MRC".

\section{Availability of data and materials}

All data generated or analysed during this study are included in this article in tables.

\section{Declarations}

\section{Ethics approval and consent to participate}

This study was approved by UKZN Biomedical Research Ethics Committee (Approval Number BE541/17) and the KwaZulu-Natal Department of Health National Health Research Database (Ref: KZ_201805_014). Participants were provided with an information sheet and were required to sign and date a declaration of informed consent form. No identifying data from the participants or patients were collected or used in this study, thus participation remained anonymous. Participation was completely voluntary, and participants were made aware that they could withdraw from the study at any stage without consequence. There were no incentives or direct benefits offered to the participants to participate.

\section{Consent for publication}

Not applicable—no images or videos presented.

\section{Competing interests}

The authors declare that there are no competing interests.

Received: 30 June 2021 Accepted: 3 December 2021

Published online: 14 December 2021

\section{References}

1. South African National Department of Health. National drug policy for South Africa. 1996. https://www.sapc.za.org/Media/Default/Documents/ Reference\%20-\%20National\%20Drug\%20Policy\%20for\%20South\%20Afr ica.pdf. Accessed 2 Mar 2019.

2. South African National Department of Health. National guideline for the establishment and functioning of pharmaceutical and therapeutics committees in South Africa. 2019. https://docs.mymembership.co.za/ docmanager/3c53e82b-24f2-49e1-b997-5a35803be10a/00143649.pdf. Accessed 21 Feb 2021.

3. Management Sciences for Health and World Health Organization. Drug and therapeutics committee training course: session 10 —standard treatment guidelines. Submitted to the U.S. Agency for International Development by the Rational Pharmaceutical Management Plus Program. 2007;2-3. https://www.who.int/medicines/technical_briefing/tbs/10-PG_ Standard-Treatment-Guidelines_final-08.pdf. Accessed 11 Feb 2020.

4. World Health Organization. Health topics: essential medicines. 2016. https://www.who.int/topics/essential_medicines/en/. Accessed 6 Feb 2020

5. South African National Department of Health. Standard treatment guidelines and essential medicines list for South Africa: hospital level adults. 2012. https://www.gov.za/documents/standard-treatment-guide lines-and-essential-medicines-list-south-africa-hospital-level. Accessed 25 Mar 2020. 
6. Gopalakrishnan S, Udayshankar PM, Rama R. Standard treatment guidelines in primary healthcare practice. Indian J Fam Med Prim Care. 2014. https://doi.org/10.4103/2249-4863.148134

7. South African National Department of Health. National Health Act (Act No, 61 of 2003). 2003. https://www.gov.za/documents/national-healthact. Accessed 21 Feb 2021

8. Perumal-Pillay VA, Suleman F. Selection of essential medicines for South Africa - an analysis of in-depth interviews with national essential medicines list committee members. BMC Health Serv Res. 2017;17:17. https:// doi.org/10.1186/s12913-016-1946-9.

9. South African National Department of Health. Restructuring the national health system for universal primary health care. 1996. https://libguides.lib. uct.ac.za/c.php?g=194637\&p=5351707. Accessed 17 May 2020.

10. The South African Nursing Council. Nursing Act 2005 (Act No. 33 of 2005). 2005. https://www.gov.za/sites/default/files/gcis_document/201409/ 36606rg9979gon452.pdf. Accessed 20 Feb 2021.

11. Lancaster R. Improving access to health treatment guidelines through mobile technology. S Afr Pharm J. 2016;83(10):42-4.

12. Le Grand A, Hogerzeil HV, Haaijer-Ruskamp FM. Intervention research in rational use of drugs: a review. Health Policy Plan. 1991;14(2):89-102. https://doi.org/10.1093/heapol/14.2.89.

13. Bazargani YT, Ewen M, de Boer A, Leufkens HGM, Mantel-Teeuwisse AK. Essential medicines are more available than other medicines around the globe. PLoS ONE. 2014;9(2): e87576. https://doi.org/10.1371/journal.pone. 0087576.

14. Murray A. Understanding the role and use of essential medicine lists [Internet]. IMS Institute for Healthcare Informatics. 2015. http://www. farmaindustria.es/web_en/wp-content/uploads/sites/3/2015/04/IH _ Essential_Medicines_Report_2015-Web3.pdf. Accessed 3 Feb 2020.

15. South African Government. National development plan 2030: our future - make it work. 2012. https://www.gov.za/documents/nationaldevelopment-plan-2030-our-future-make-it-work. Accessed 2 Mar 2020.

16. South African National Department of Health. National health insurance 2015. Retrieved from https:/www.gov.za/sites/default/files/nationalhe althinsurance.pdf. Accessed 8 Feb 2020.

17. World Health Organization. WHO medicines strategy — countries at the core: 2004-2007. 2007. http://www.who.int/management/background_ 4a.pdf. Accessed 25 Mar 2019.

18. Shuttleworth, M. Descriptive research design [Internet]. 2008. https:// www.explorable.com/descriptive-research-design Accessed 25 Mar 2019

19. KwaZulu Natal Department of Health website. Ngwelezana hospital. http://www.kznhealth.gov.za/ngwelezanahospital.htm. Accessed 24 May 2020

20. South African Drug Action Programme. South Africa: getting essential medicines to the people. Essent Drugs Monit. 1999;27. http://digicollec tion.org/hss/en/d/Jh1467e/2.3.html. Accessed 4 May 2021.

21. Taherdoost H. Sampling methods in research methodology; how to choose a sampling technique for research. SSRN Electron J. 2016. https:// doi.org/10.2139/ssrn.3205035.

22. Health Professions Council of South Africa. Guidelines for good practice in the health care professions: guidelines on the keeping of patient records. 2016. https://www.hpcsa.co.za/Uploads/Professional_Practice/ Conduct\%20\%26\%20Ethics/Booklet\%209\%20Keeping\%20of\%20Pat ient\%20Records\%20September\%20\%202016.pdf. Accessed 6 Feb 2021.

23. South African National Department of Health. National Core Standards for health establishments in South Africa. 2011. http://www.rhap.org. za/wp-content/uploads/2014/05/National-Core-Standards-2011-1.pdf. Accessed 4 Apr 2019

24. Wilson LT. Descriptive statistics [Internet]. 2010. https://www.explorable. com/descriptive-statistics. Accessed 2 Mar 2019.

25. Loke YK, Ritter JM. Two cheers or three for treatment guidelines? Nudging prescribers in right directions. Br J Clin Pharmacol. 2011;72(6):869-70. https://doi.org/10.1111/j.1368-2125.2011.04122.x.

26. World Health Organization. Global action plan for the prevention and control of noncommunicable diseases 2013-2020. 2013. https://www. who.int/publications/i/item/9789241506236 Accessed 24 Jan 2021.

27. Meyer JC, Schellack N, Stokes J, Lancaster R, Zeeman H, Defty D, Godman B, et al. Ongoing initiatives to improve the quality and efficiency of medicine use within the public healthcare system in South Africa; A preliminary study. Front Pharmacol. 2017;8:751. https://doi.org/10.3389/ fphar.2017.00751.
28. Gray A, Suleman F, Pharasi B. South Africa's National Drug Policy: 20 years and still going? S Afr Health Rev. 2017. https://www.hst.org.za/publicatio ns/South\%20African\%20Health\%20Reviews/5_South\%20Africas\%20Nat ional\%20Drug\%20Policy_20\%20years\%20and\%20still\%20going.pdf. Accessed 24 May 2020.

29. Hassan A, Abdullahi GA, Ahmed AA, Sabiu A, John U, Ezekeil G, et al. Assessing prescriber's awareness of essential medicine list, hospital drug formulary and utilization of standard treatment guidelines in a tertiary healthcare facility in North-Central Nigeria. Alex J Med. 2018;54(1):81-4. https://doi.org/10.1016/j.ajme.2017.03.006.

30. Mashalla YJ, Sepako E, Setlhare V, Chuma M, Bulang M, Massele AY. Availability of guidelines and policy documents for enhancing performance of practitioners at the Primary Health Care (PHC) facilities in Gaborone, Tlokweng and Mogoditshane, Republic of Botswana. J Public Health Epidemiol. 2016;8(8):127-35. https://doi.org/10.5897/JPHE2016.0812.

31. Awad Al, Ball DE, Eltayeb IB. Improving rational drug use in Africa: the example of Sudan. East Mediterr Health J. 2005. https://doi.org/10.26719/ 2007.13.5.1202.

32. South African Drug Action Programme. First report. The impact of the essential drugs programme in seven provinces of South Africa. 1998a.

33. South African Drug Action Programme. Mid-term joint review of the South African Drug Action Programme. 1998b.

34. South African National Department of Health. Impact of the essential drugs programme at primary health care level in South Africa: key findings and recommendations of surveys in 2003. 2003. http://archives.who. int/icium/icium2004/resources/ppt/AC027.ppt. Accessed 22 Jan 2021.

35. Peltzer K, Phaswana-Mafuya N, Mohlala G, Ramlagan S, Davids A, Zuma $\mathrm{K}$, et al. Impact of the National Drug Policy on pharmaceuticals in two provinces in South Africa. Human Sciences Research Council. 2005. http://www.hsrc.ac.za/en/research-outputs/ktree-doc/1294. Accessed 22 Jan 2021.

36. Sooruth UR, Sibiya MN, Sokhela DG. The use of standard treatment guidelines and essential medicines list by professional nurses at primary healthcare clinics in the uMgungundlovu district in South Africa. Int J Afr Nurs Sci. 2015;3:50-5. https://doi.org/10.1016/j.ijans.2015.08.001.

37. Gasson J, Blockman M, Willems B. Antibiotic prescribing practice and adherence to guidelines in primary care in Cape town metro district, South Africa. S Afr Med J. 2018;108(4):304-10. https://doi.org/10.7196/ SAMJ.2017.v108i4.12564.

38. Bamiselu OF, Ajayi I, Fawole O, Dairo D, Ajumobi O, Oladimeji A, Steven Y. Adherence to malaria diagnosis and treatment guidelines among healthcare workers in Ogun State, Nigeria. BMC Public Health. 2016;16:828-828. https://doi.org/10.1186/s12889-016-3495-x.

39. De Bruycker M, Van den Bergh R, Dahmane A, Khogali M, Schiavetti, Nzomukunda $Y$, et al. Non-adherence to standard treatment guidelines in a rural paediatric hospital in Sierra Leone. Public Health Act. 2013;3(2):11824. https://doi.org/10.5588/pha.12.0060.

40. Schuster MA, McGlynn EA, Brook RH. How good is the quality of health care in the United States? Milbank Q. 1998;76(4):517-63. https://doi.org/ 10.1111/1468-0009.00105.

41. Walther D, Curjuric I, Dratva J, Schaffner E, Quinto C, Rochat T, et al. High blood pressure: prevalence and adherence to guidelines in a populationbased cohort. Swiss Med Wkly. 2016;146: w14323. https://doi.org/10. 4414/smw.2016.14323.

42. Younis MZ, Hamidi S, Forgione D, Hartmann M. Rational use effects of implementing an essential medicines list in West Bank, Palestinian Territories. Expert Rev Pharmacoecon Outcomes Res. 2009;9(3):243-50. https:// doi.org/10.1586/erp.09.21.

43. Baiardini I, Braido F, Bonini M, Compalati E, Canonica GW. Why do doctors and patients not follow guidelines? J Allergy Clin Immunol. 2009;9(3):228-33. https://doi.org/10.1097/ACl.0b013e32832b4651.

44. Boonstra E, Lindbaek M, Khulumani P, Ngome E, Fugelli P. Adherence to treatment guidelines in primary health care facilities in Botswana. Trop Med Int Health. 2002;72(2):178-86. https://doi.org/10.1046/j.1365-3156. 2002.00842.x

45. Cassimjee M, Suleman F. Adherence to hypertension treatment guidelines in state facilities in KwaZulu-Natal, South Africa. J Eval Clin Pract. 2009;15(6):1077-81. https://doi.org/10.1111/j.1365-2753.2009.01123.x.

46. Hlongwana S, Bezuidenhout S, Helberg E. Adherence to the primary health care standard treatment guidelines in a paediatric sample with respiratory conditions in Umkhanyakude health district, KwaZulu Natal, 
South Africa: increasing patient access to treatment. Afr J Phys Health Educ Recreat Dance. 2015;21(2):330-42.

47. Reddy K, Patrick ME, Stephen CR. Management of acute diarrhoeal disease at Edendale Hospital: are standard treatment guidelines followed? S Afr J Child Health. 2016;10(4):215-20. https://doi.org/10.7196/sajch.2016. v10i4.1177.

48. Siko PR, van Deventer C. Compliance with standard treatment guidelines in the management of hypertension: a review of practice of healthcare workers in Potchefstroom, North West Province, South Africa. S Afr Fam Pract. 2017;59(2):72-7. https://doi.org/10.1080/20786190.2016.1272246.

49. Norushe TF, van Rooyen D, Stumpher J. In-service education and training as experienced by registered nurses. Curationis. 2004;27(4):63-70. https:// doi.org/10.4102/curationis.v27i4.1022.

50. Summers RS, Moller H, Meyer D \& Botha R. "Contracting-out" drug procurement and distribution: experience with a primary distributor system in South Africa. Essent Drugs Monit. 1998;25-26

51. World Health Organization. Indicators for monitoring national drug policies: a practical manual. 2nd ed. 1999. https://apps.who.int/iris/handle/ 10665/60706. Accessed 3 Feb 2020.

\section{Publisher's Note}

Springer Nature remains neutral with regard to jurisdictional claims in pub-

lished maps and institutional affiliations.

- fast, convenient online submission

- thorough peer review by experienced researchers in your field

- rapid publication on acceptance

- support for research data, including large and complex data types

- gold Open Access which fosters wider collaboration and increased citations

- maximum visibility for your research: over 100M website views per year

At BMC, research is always in progress.

Learn more biomedcentral.com/submissions 